Revista Brasileira de Agricultura Irrigada v.6, nº 1, p.14- 22 , 2012

ISSN 1982-7679 (On-line)

Fortaleza, CE, INOVAGRI - http://www.inovagri.org.br

Protocolo 075/11 - 29/11/2011 Aprovado em 19/03/2012

\title{
TOLERÂNCIA DE GENÓTIPOS DE CITROS AO ESTRESSE HÍDRICO NA FASE DE PORTA-ENXERTO
}

\author{
Ana Kelliane Silva do Nascimento ${ }^{1}$, Pedro Dantas Fernandes ${ }^{2}$, \\ Janivan Fernandes Suassuna ${ }^{3}$, Ana Cristina Macedo de Oliveira ${ }^{4}$, \\ Monica Shirley da Silva Sousa ${ }^{3}$, Claudia Albuquerque Carvalho Melo ${ }^{5}$
}

\begin{abstract}
RESUMO
Estudou-se a tolerância ao estresse hídrico de 8 genótipos de citros na fase de porta enxertos, em experimento desenvolvido em casa de vegetação da UAEAg/CTRN da UFCG com delineamento experimental em blocos casualizados com três repetições, num esquema fatorial de dois tratamentos (EH1: testemunhas irrigadas a $100 \%$ da Capacidade Campo (CC) durante todo o experimento e EH2:irrigação limitada a 50\% da CC durante 51 dias e em seguida, a $25 \%$ da CC) e três genótipos. Cada unidade experimental constou de 10 plantas úteis. Observando os efeitos do estresse hídrico nos genótipos de citros com potencialidades a porta enxertos nas variáveis de crescimento, destaca-se o genótipo 15 (TSKC x CTARG - 019), com as maiores médias. O Limoeiro Cravo foi o que teve maior sensibilidade ao estresse em todas as variáveis, denotando sensibilidade ao estresse hídrico.
\end{abstract}

Palavras-chave: Citrus sp, crescimento, tolerância.

\section{CITRUS GENOTYPES OF TOLERANCE TO WATER STRESS PHASE ROOTSTOCK}

\begin{abstract}
We studied the water stress tolerance of eight genotypes of citrus rootstocks on stage, in an experiment conducted in a greenhouse at UAEAg / CTRN UFCG with the experimental design in blocks with three replications in a factorial of two treatments (EH1 : witnesses irrigated at $100 \%$ Field Capacity (CC) throughout the experiment and $\mathrm{EH} 2$ : limited irrigation at $50 \%$ DC for 51 days and then $25 \%$ of DC) and three genotypes. Each experimental unit consisted of 10 plants. Observing the effects of water stress in citrus genotypes with the potential rootstocks on growth variables, we highlight

\footnotetext{
${ }^{1}$ Mestre, Gerente da Qualidade LEMI/ESALQ, Piracicaba - São Paulo. Email: kellycentec@yahoo.com.br.

${ }^{2}$ Doutor, Pesquisador do INSA, Campina Grande - Paraíba.

${ }^{3}$ Mestrando UAEAg/CTRN/UFCG. Campina Grande - Paraíba.

${ }^{4}$ Doutorando, UAEAg/CTRN/UFCG. Campina Grande - Paraíba.

${ }^{5}$ Acadêmica de Engenharia Agronômica, UFC- Fortaleza Ceará.
} 
the genotype 15 (TSKC CTARG $x$ - 019), with the highest averages. The Rangpur lime was the one most sensitive to stress in all variables, showing sensitivity to water stress.

Keywords: Citrus sp., growth, tolerance.

\section{INTRODUÇÂO}

No Nordeste brasileiro, o recurso água é limitado e a distribuição das chuvas, na maioria dos Estados, não supre adequadamente às necessidades hídricas das culturas durante todo o ano, interferindo no crescimento e desenvolvimento da planta (MIRANDA et al., 2004; AZEVEDO et al., 2005).

É incontestável a importância socioeconômica da citricultura no Nordeste brasileiro; no entanto, a produtividade é considerada baixa em razão, principalmente, do déficit hídrico que ocorre durante mais de seis meses do ano, coincidindo, em geral, com temperaturas elevadas (CRUZ et al., 2003).

De acordo com Nogueira et al. (2001), genótipos que apresentem diversidade na resposta ao estresse hídrico constituem excelentes materiais para serem utilizados em programas de melhoramento genético. Vários caracteres fisiológicos podem ser empregados na avaliação das respostas das espécies vegetais ao estresse hídrico destacando-se, entre eles, o potencial hídrico foliar, a condutância estomática e a transpiração. Em porta-enxertos cítricos, Pereira et al. (2003) recomendam avaliar o crescimento do sistema radicular e da parte aérea, com base no acúmulo de matéria seca, e do incremento da área foliar.

A diversificação de genótipos cítricos no Brasil, como um todo, também fica a desejar, apesar da grande variabilidade genética existente nos bancos de germoplasma distribuídos no País; a combinação "laranja Pera" x "limão Cravo" é predominante, chegando a níveis quase absolutos, observando-se uma recente tendência de mudanças, especialmente no que diz respeito ao uso de porta-enxertos, pelo surgimento da morte súbita dos citros em plantas enxertadas em limão 'Cravo'.

Assim, este trabalho teve como objetivo avaliar a tolerância ao estresse hídrico de genótipos cítricos (variedades e híbridos) com potencialidade de serem utilizados como porta-enxertos.

\section{MATERIAL E MÉTODOS}

A pesquisa foi conduzida em ambiente protegido (casa de vegetação) do Centro de Tecnologia e Recursos Naturais - CTRN da UFCG, localizado no município de Campina Grande - PB. Os genótipos utilizados foram fornecidos pelo Programa de Melhoramento Genético de Citros da Embrapa Mandioca e Fruticultura Tropical, sendo estes: 4- LVK (limoeiro volkameriano) x LCR (limoeirocravo) - 018, 5- LCR x CTYM (citrange Yuma)- 005, 7- TSKC x CTSW (citrumelo swingle) - 018, 11- TSKFL (tangerina sunki da flórida) x CTTR - 017, 15TSKC x CTARG (citrange argentino) 019, 16- CITRANGE, 20- TSKC x CTSW - 041 e o 25- LIMOEIRO-CRAVO SANTA CRUZ - PADRÃO sendo este utilizada como testemunha durante $\mathrm{o}$ transcorrer do experimento.

$\mathrm{O}$ experimento foi em blocos casualizados, com três repetições, em esquema fatorial (2 níveis de estresse hídrico x 3 genótipos), sendo a unidade experimental constituída por dez recipientes (tubetes) cada um contendo uma planta.

Foram estudados dois níveis de estresse hídrico sendo $\mathrm{H}_{1}$ - testemunha, irrigação das plantas com $100 \%$ da Capacidade Campo (CC) durante todo o transcorrer do experimento; $\mathrm{H}_{2}-$ irrigação limitada a $50 \%$ da CC, durante 51 dias, e, em seguida, a $25 \%$ da CC durante 64 dias. As sementes 
foram germinadas em uma mistura de solo e substrato; o solo coletado no Campus da UFCG misturado a um substrato comercial composto por vermiculita, casca de pinus e húmus, na proporção de 1:1, para enchimento dos tubetes. A irrigação foi feita através da diferença entre o peso médio do solo de 5 tubetes na capacidade de campo e do peso seco ao ar. Depois de estabelecido o valor médio necessário para atingir a $\mathrm{CC}$, a irrigação foi feita mediante diferença diária dos pesos reais.

A cada 17 dias após semeadura (DAS) foram mensurados a altura de planta $(\mathrm{cm})$, o diâmetro do caule a uma altura de $5 \mathrm{~mm}$ e contado o número de folhas. Avaliou-se também a Fitomassa seca da folha (FF), a Fitomassa seca do caule (FC), a Fitomassa seca da raiz (FR), a Fitomassa seca total (FST) (somatório de FF, FC, FR) e a razão entre a FR e a Fitomassa seca da parte aérea (somatório de FR e FC), obtendo a relação raiz parte aérea (R/PA). Os dados foram avaliados por análise de variância, teste F com auxilio do software SISVAR. Para avaliar o efeito comparativo do estresse hídrico entre os genótipos, procedeu-se a comparação de médias pelo Scott-Knott $5 \%$ de probabilidade.

\section{RESULTADOS E DISCUSSÃO}

Estudando-se o efeito do estresse hídrico nos genótipos a partir de 125 dias após semeadura (DAS) pelo teste de médias (Skott Knott) observou-se que o genótipo 15 (TSKC x CTARG 019), foi o que obteve menor redução do numero de folhas entre os tratamentos com e sem estresse, de $21,8 \%$. Brito et al. 2008, estudando salinidade nos citros, observou maior potencial para produção de folhas nos híbridos de tangerina Sunki, com citrange Argentino, fato que pode ser relacionado ao vigor híbrido referente ao cruzamento.

O genótipo CITRANGE decresceu $34,35 \%$ e os cruzamentos de trifoliatas com citrumelo swingle tiveram decréscimo de $36 \%$. A testemunha Limão Cravo reduziu 44,12\%. Observa-se ainda, na Figura 1, que sob condição de estresse os genótipos '11' e '25', a partir dos 193 e 159 DAS, respectivamente, estabilizaram o número de folhas, fato que pode ser considerado uma resposta de adaptação ao estresse hídrico, chamado aclimatação; tal processo requer gasto energético, resultando em redução do crescimento (LACHER, 2000). Os cruzamentos de Limoerio Volkameriano com limão cravo e Limoerio Volkameriano com Cintrange Yuma obtiveram maior decréscimo do número de folhas de 42,15 e 52,63\%, respectivamente.

Os genótipos oriundos de trifoliatas, sob condições de estresse hídrico apresentaram maiores números de folhas, fato observado também por Brito (2007), cujos híbridos provenientes de Trifoliata em condições de salinidade tiveram alta capacidade de emissão de folhas, e Schäfer et al. (2006), trabalhando com genótipos diferentes de porta-enxerto cítricos com variação de substratos, constataram maior número de folhas nos oriundos de Trifoliata. 
PORTA-ENXERTO
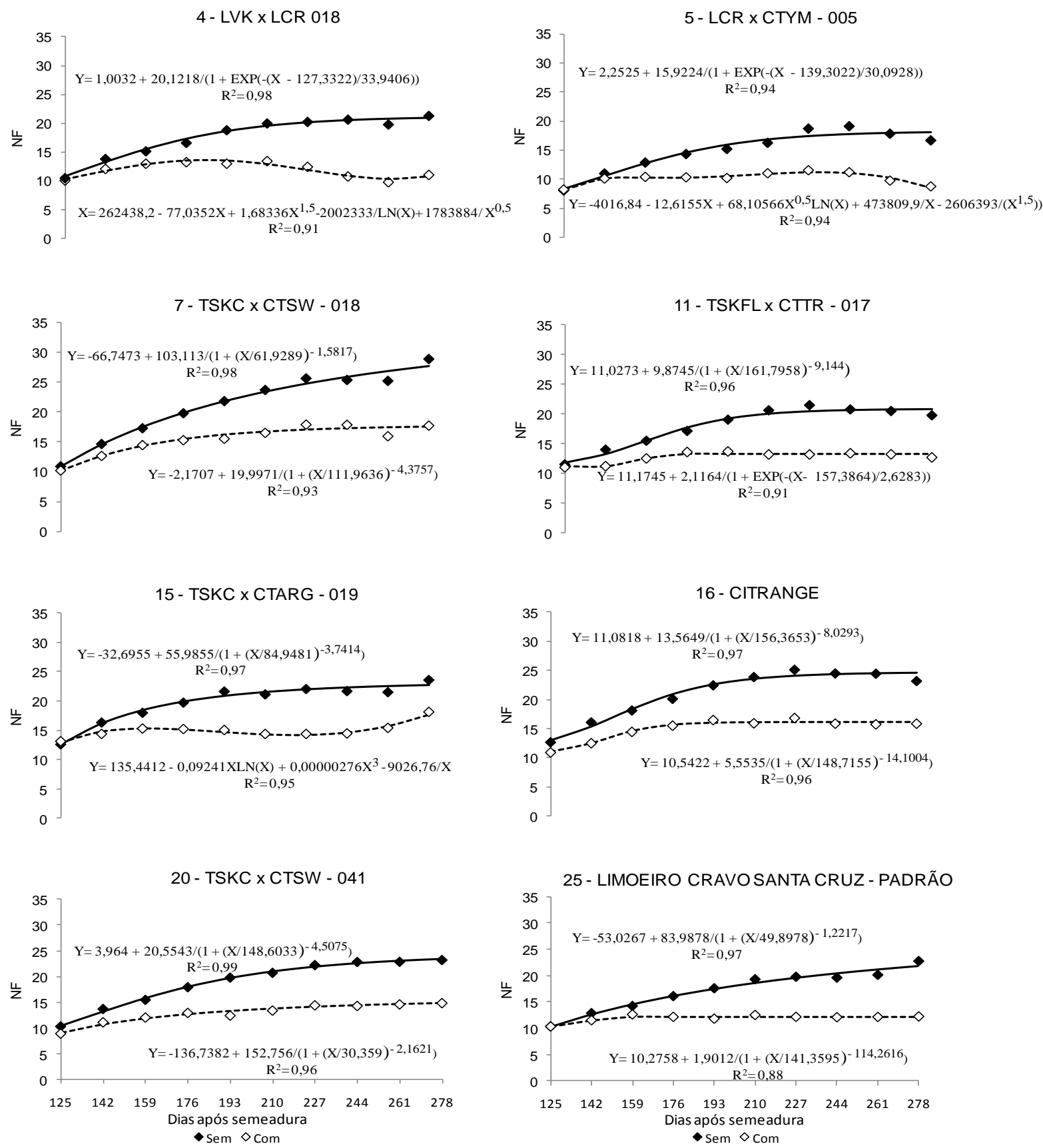

Figura 1. Crescimento em NF, utilizando-se as médias do fator hídrico obtido no período estudado (dos 125 aos 278 DAS), para os genótipos estudados.

Maior crescimento em altura de planta foi registrado no genótipo 20 (TSKC x CTSW 041), apresentando aos 278 DAS, redução de 29,3\% (Figura 2). Os genótipos 11 (TSKFL x CTTR 017) e 25 (Limoeiro Cravo) foram os que apresentaram maior sensibilidade ao estresse hídrico, com redução de 40,9 e $51,39 \%$, respectivamente. Brito 2008, estudando salinidade em citros observou maior altura de planta para $\mathrm{o}$ cruzamento de TSKC x CTARG - 081 . O mesmo autor estudando salinidade observou para o Limão Cravo altura de $27,3 \mathrm{~cm}$, valor maior que o encontrado nesse trabalho, que aos 278 DAS o referido genótipo apresentou, sob condição de estresse hídrico, altura de $16,5 \mathrm{~cm}$ (Figura 2). 

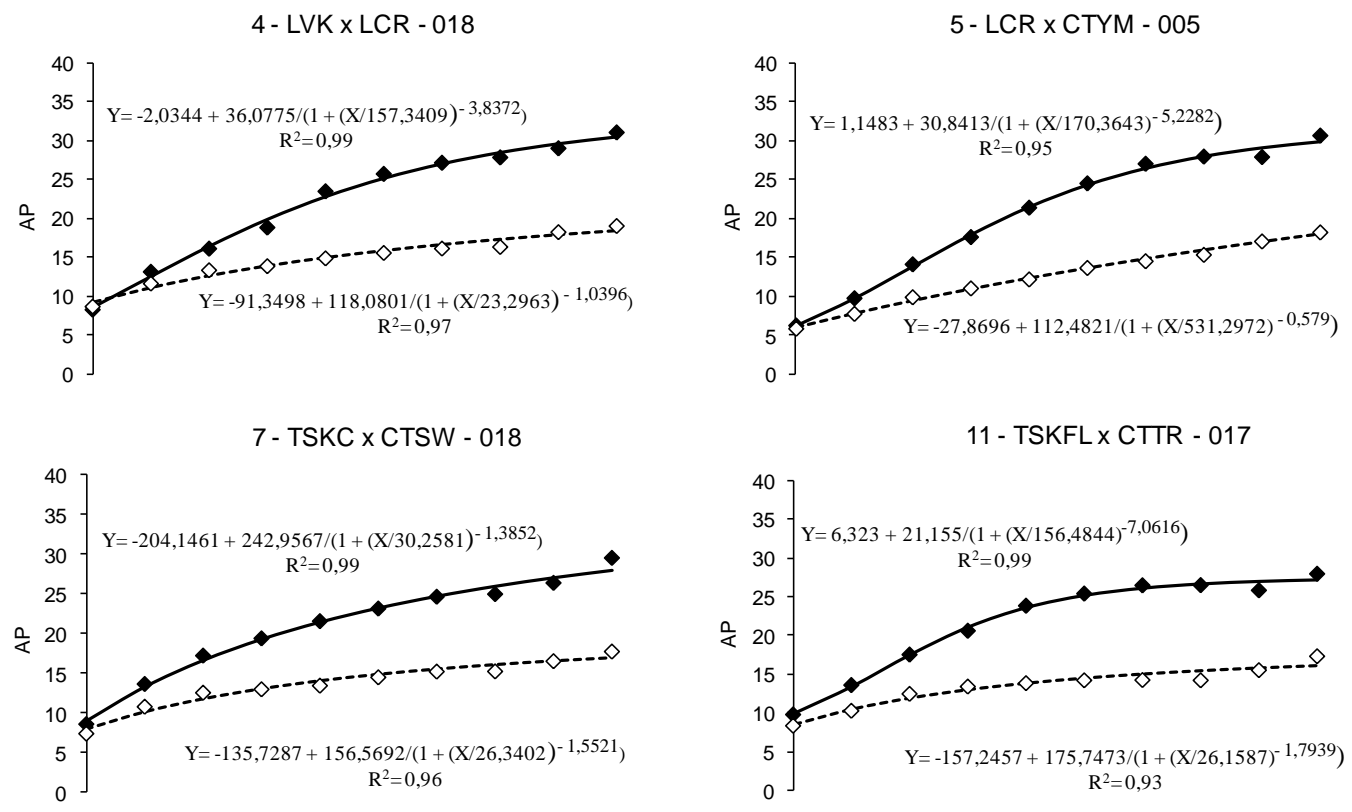

11 - TSKFL x CTTR - 017

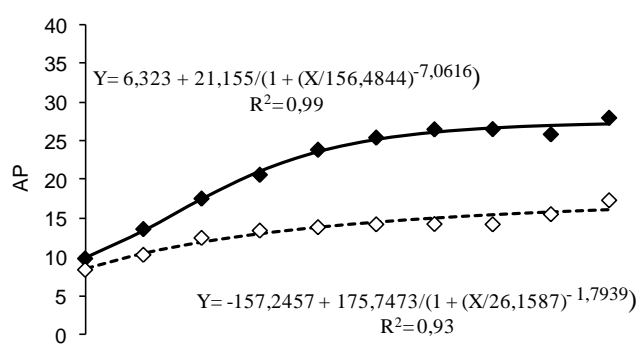

15 - TSKC x CTARG - 019

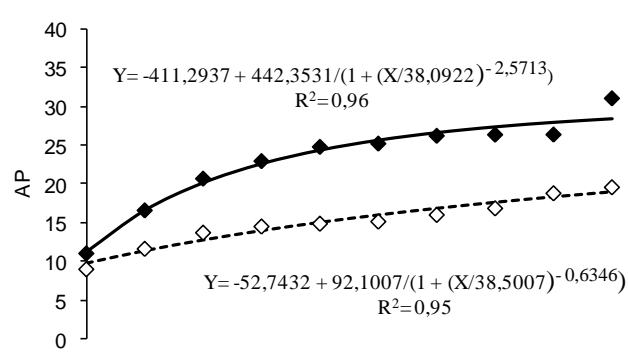

16 - CITRANGE

$20-$ TSKC $\times$ CTSW - 041
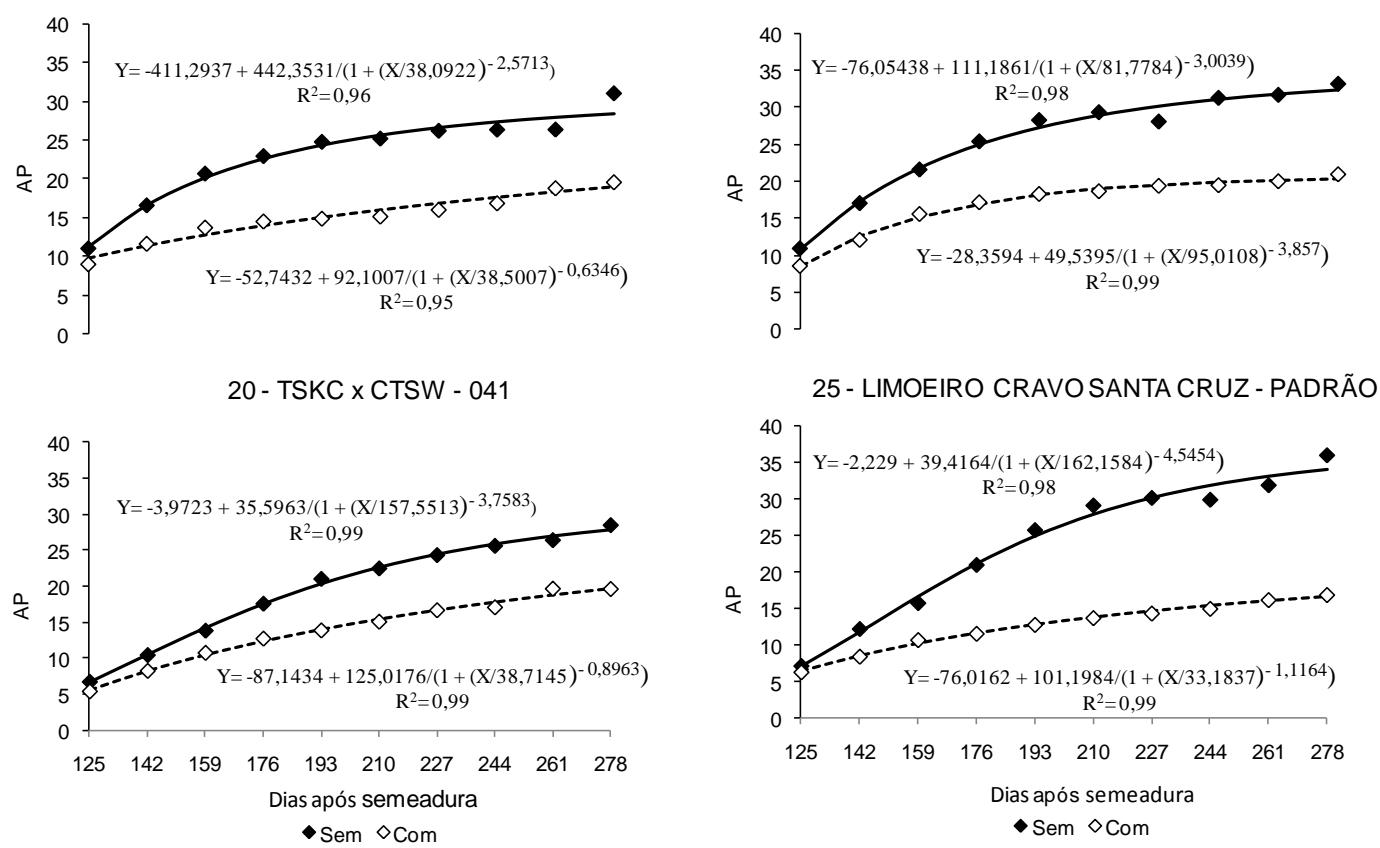

Figura 2. Crescimento em AP, utilizando-se as médias do fator hídrico obtido no período estudado (dos 125 aos 278 DAS), para os genótipos estudados.

O Genótipo 16 (CITRANGE), embora tenha apresentado aos 278 DAS valor elevado para altura de planta sob condição de estresse $(20,6 \mathrm{~cm})$, apresentou alto decréscimo quando irrigado sem estresse, 36,9\%. Schafer 2000, aos 197 DAS, estudando o cultivo de porta-enxerto em casa de vegetação conseguiu altura de planta de aproximadamente $10 \mathrm{~cm}$ para $\mathrm{o}$ "Trifoliata"; de $9 \mathrm{~cm}$ para o "Troyer" e de $11 \mathrm{~cm}$ para o "Swingle", médias inferiores encontradas nesse trabalho, que aos 193 DAS, apresentou média de $18 \mathrm{~cm}$ 
para trifoliatas, $19 \mathrm{~cm}$ para Troyer e $17 \mathrm{~cm}$ para Swingle, o que pode esta relacionado a seus respectivos vigores-híbridos.
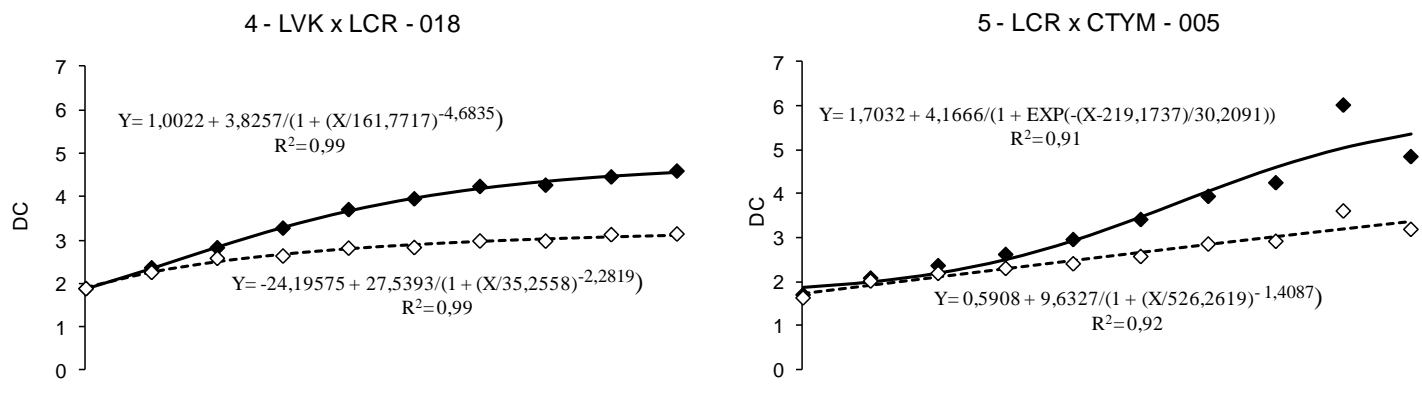

7 - TSKC x CTSW - 018

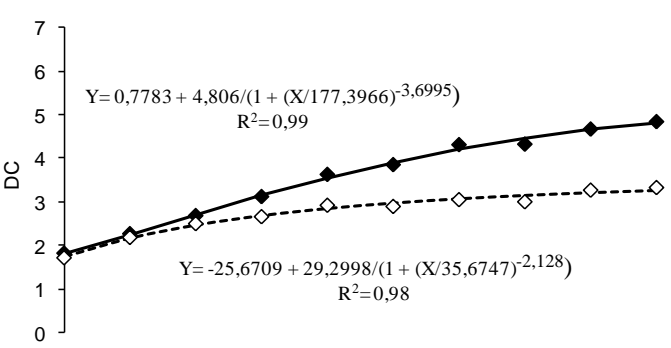

15 - TSKC x CTARG - 019

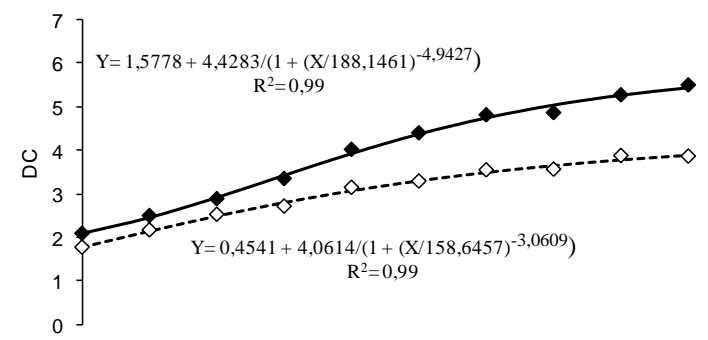

20 - TSKC x CTSW - 041

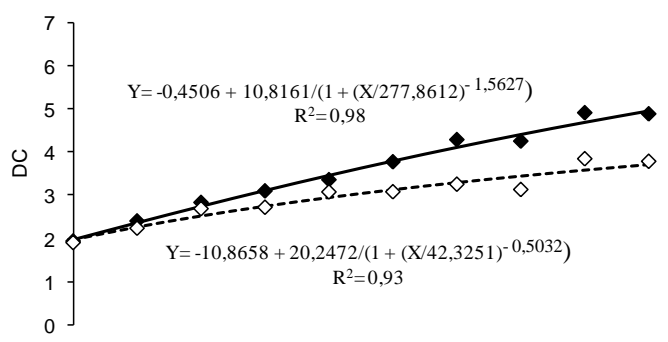

16 - CITRANGE

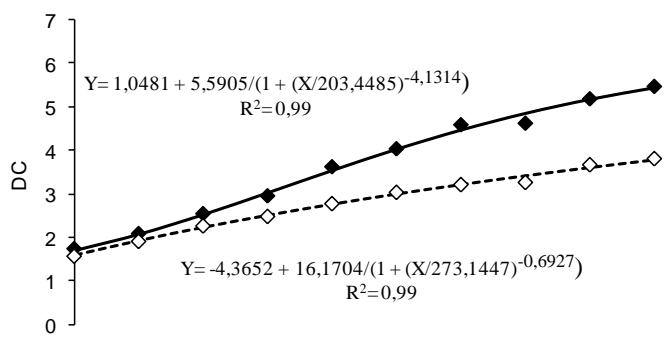

25 - LIMOEIRO CRAVO SANTA CRUZ - PADRÃO
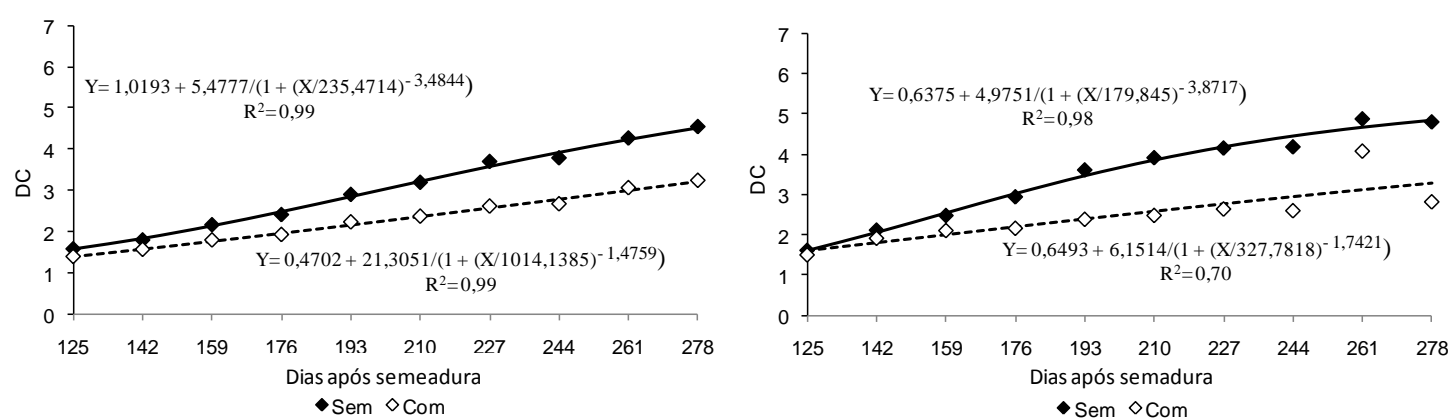

Figura 3. Crescimento em DC, utilizando-se as médias do fator hídrico obtido no período estudado (dos 125 aos 278 DAS), para todos os genótipos estudados.

O efeito do estresse hídrico proporcionou decréscimo no diâmetro de caule (DC) em todos os genótipos, sendo o genótipo 15 (TSKC x CTARG 019), o que apresentou menor redução entres os tratamentos sem e com estresse, de $28,49 \%$ e as maiores médias de DC. Brito 2007, estudando salinidade em citros achou melhores valores de DC nesse mesmo genótipo e no genótipo Limoeiro Cravo Santa cruz, entretanto, neste trabalho o Limão Cravo demonstrou alta sensibilidade ao estresse, com redução, entre os tratamentos, de 32,09\%. Schmitz (1998), trabalhando com Trifoliata sob diferentes 
substratos, encontrou valores de 1,97 mm de diâmetro, valores inferiores aos encontrado nesse trabalho, que aos 150 DAS os valores de diâmetros estiveram entre 1,97 e $2,72 \mathrm{~cm}$ e ao final da pesquisa (278 DAS) os valores médios foram entre 3,82 e $4,66 \mathrm{~cm}$, inferindo que os genótipos, destacando os oriundos de Trifoliatas, demonstraram bom desenvolvimento mesmo sob condições de estresse hídrico.

$\mathrm{Na}$ Fitomassa das Folhas os genótipos apresentam redução no peso das folhas em vários graus de diferença. O genótipo 7 ( TSKC x CTSW 018) foi o que obteve maior peso de Fitomassa das folhas, com 3,26 g, apresentando redução entre o início e o fim da pesquisa de 19,11\%. Os genótipos 6 (TSKC x CTTR 028) e 20 (TSKC x CTSW 041) obtiveram redução de 20,37 e $19,69 \%$. Brito 2007, estudando salinidade, encontrou redução de $6,19 \%$ para o genótipo TSKC $\mathrm{x}$ CTTR 028, demonstrando maior sensibilidade desse genótipo ao estresse hídrico. $\mathrm{O}$ mesmo autor encontrou para o cruzamento de Tangerina Sunki com Citrumelo Swingle redução de $7,75 \%$, demonstrando que este genótipo também foi mais sensível ao estresse hídrico. O limoeiro cravo foi o que teve maior redução em $\mathrm{FF}$, de $61,38 \%$, apresentando também baixos valores para o número de folhas.

Na Fitomassa do Caule (FC) os genótipos que apresentaram melhor desenvolvimento foram os genótipos 4 (LVK x LCR 018), 7 (TSKC x CTSW 018), 16 (CITRANGE), 20 (TSKC $\mathrm{X}$ CTSW 041) e 25 ( Limoeiro-cravo santa cruz), com 2,62, 2,97, 2,59, 2,59 e 2,44 g, respectivamente. Os genótipos que apresentaram as menores médias para FC foram: 5 (LCR x CTYM 005), 11 (TSKFL x CTTR 017) e 15 (TSKC x CTARG 019), com 1,92, 1,70, 2,04 g, nesta ordem. Brito 2007, estudando salinidade em porta-enxertos de citros, encontrou menor média para a
Fitomassa seca do caule em genótipo oriundo de cruzamento de tangerina Sunki e Troyer, resultado também encontrado neste trabalho.

Na Fitomassa Seca da Raiz, o genótipo 7 (TSKC x CTSW 018), apresentou maior Fitomassa com peso de $3,17 \mathrm{~g}$ demonstrando que este genótipo apresenta maior profundidade e ramificação do sistema radicular, mecanismos de tolerância ao estresse.

Os genótipos 4 (LVK x LCR 018), 16 (CITRANGE), 20 (TSKC x CTSW 041) e 25 (LIMOEIRO-CRAVO SANTA CRUZ) obtiveram Fitomassa de 2,55, 2,65, 2,54 e 2,39 g, respectivamente. Os genótipos que apresentaram menores médias para esta variável foram os 5 (LCR x CTYM 005), o 11 (TSKFL x CTTR 017) e o 15 (TSKC x CTARG 019), com 1,53, 1,69 e 1,92 g. Como a massa seca das raízes desses genótipos foi menor, as raízes sob estresse devem ser mais finas; Hsiao e $\mathrm{Xu}$ (2000), também observaram raízes mais finas sob estresse hídrico.

Na Fitomassa seca total (FST) o genótipo 7 (TSKC x CTSW 018), assim como nas variáveis FF, FC e FR obteve menor redução, entre os tratamentos sem e com estresse, de 25,92\%, demonstrando que esse genótipo apresenta características de resistência ao estresse hídrico.

O genótipo 15 (TSKC x CTARG 019), embora esteja entre os que tiveram menores valores de FST, apresentando diferença de apenas $26,82 \%$, considerado resistente ao estresse, porém, pouco produtivo, pois apresenta médias baixas de FST.

Os genótipos 5 (LVK x CTYM 00 5) e 11 (TSKFL x CTTR 017) foram os que apresentaram as menores médias de FST, para os dois tratamentos; o tratamento com estresse resultou numa redução de 49,13 e 47,58\%, respectivamente, notando que esses genótipos foram pouco produtivos $\mathrm{e}$ 
apresentam características sensíveis ao estresse. Os genótipos 4 (LVK x LCR 018) e 25 (LIMOEIRO-CRAVO SANTA CRUZ) foram os genótipos que apresentaram as maiores reduções no tratamento com estresse, de 51,86 e $57,44 \%$ demonstrando alto nível de sensibilidade ao estresse.

Observa-se que, sob efeito do estresse hídrico, a Fitomassa seca mostrou redução tal como foi observado por Peixoto et al. (2006), ao notarem decréscimo da matéria seca em genótipos de citros sob efeito de estresse hídrico, confirmando os resultados encontrados neste trabalho, e por Paim (2002) em aroeira-do-sertão (Myracrogruon urundeuva Fr. AII.), sendo a matéria seca vegetal um dos parâmetros mais significativos na mensuração das alterações do crescimento vegetal.

Sob condição de estresse, os genótipos de citros que apresentaram maiores médias para relação R/PA, foram os genótipos 4 (LVK x LCR 018), 7 (TSKC $\mathrm{x}$ CTSW 018), 11 (TSKFL $\mathrm{x}$ CTTR 017), 16 (CITRANGE), e 25 (LIMOEIRO-CRAVO SANTA CRUZ).

O genótipo 5 (LCR x CTYM 005)

foi o que apresentou menor média, tanto sob condição de estresse como sem estresse; o genótipo 16 apresentou maior média para a relação R/PA, quando irrigado sem estresse; já o 5 e o 25 apresentaram os menores valores, nessa mesma condição. Os genótipos 4, 6, 7, $11,15,20$ e 17, apresentaram baixos valores, resultado indicativo de que a raiz desses genótipos sofreu mais o efeito do estresse que a parte aérea.

Para Marschner (1995), que maior crescimento radicular pode levar à exploração de um volume maior do solo, favorecendo a absorção de água e de elementos essenciais, sendo particularmente importantes em solos que apresentam limitada capacidade de fornecimento de nutrientes, podendo beneficiar o crescimento das plantas.

\section{CONCLUSÕES}

Os genótipos trifoliatas são os menos afetados pelo estresse hídrico.

Os genótipos 7 (TSKC x CTSW 018) e 15 (TSKC x CTARG 019) se destacaram por apresentarem resistência ao estresse.

O genótipo 25 (LIMOEIRO CRAVO SANTA CRUZ) sofreu consideráveis reduções em todas as variáveis estudadas, denotando sensibilidade ao estresse hídrico.

\section{REFERÊNCIAS BIBLIOGRÁFICAS}

AZEVEDO, B. M.; BASTOS, F. G. C.; VIANA, T. V. A.; RÊGO, J. L.; D'ÁVILA, J. H. Efeitos de níveis de irrigação na cultura da melancia. Revista Ciência Agronômica, v. 36, n. 1, p. 9-15, 2005.

BRITO, M. E. B. Tolerância de Porta-Enxertos de Citros à Salinidade. 2007. número de páginas. Dissertação de mestrado. Universidade Federal de Campina Grande, Campina Grande, 2007.

BRITO, M. E. B.; FERNADES, P. D.; GHEYI,H.R.; MELO, A. S.; CARDOSO, J. A. F.; SOARES FILHO, W.S.; Sensibilidade de Variedades e Híbridos de Citrange à Salinidade na Formação de porta-enxertos. Revista Brasileira de Ciências Agrárias, v. 3, n. 4, p. 343-353, 2008.

CRUZ, J. L.; PELACANI, C. R.; SOARES FILHO, W. S.; CASTRO NETO, M. T.; COELHO, E. F.; DIAS, A. T.; PAES, R. A. Produção e partição de matéria seca e abertura estomática do limoeiro Cravo submetido a estresse salino. Revista Brasileira de Fruticultura, v. 25, n. 3, p. 528-531, 2003.

HSIAO, T. C.; XU, L. K. Sensitivity of growth of roots versus 
leaves to water stress: biophysical analysis and relation to water transport. Journal of Experimental Botany, Oxford, v. 51, p. 1595-1616, 2000.

\section{LARCHER, W. Ecofisiologia} vegetal. Trad. Carlos Henrique B. A. Prado. São Carlos: RIMA p. 531,2000.

MARSCHNER, H. Mineral nutrition of higher plants. 2.ed. Berna: International Potash Institute, 1995. 680 p.

MIRANDA, F. R.; OLIVEIRA, J. J.; SOUZA, F. Evapotranspiração máxima e coeficientes de cultivo para a cultura da melancia irrigada por gotejamento. Revista Ciência Agronômica, v. 35, n. 1, p. 36-43, 2004.

NOGUEIRA, R. J. M. C.; MORAES, J. A. P. V.; BURITY, H. A. Alterações na resistência à difusão de vapor das folhas e relações hídricas em aceroleira submetidas a déficit de água. Revista Brasileira de Fisiologia Vegetal, Londrina, v. 13, n. 1, p. 75-87, 2001.

PAIM, A. C. B. Avaliação do efeito do estresse hídrico na estrutura, ecofisiologia e na bioquímica de plântulas de Myracrodruon urundeuva Fr. All. (ANACARDIACEAE). Feira de Santana, Dissertação (Mestrado), Universidade Estadual de Feira de Santana, 2002. 80 p.
PEIXOTO, C. P.; CERQUEIRA, E. C.; SOARES FILHO, W. S.; CASTRO NETO, M. T.; LEDO, C. A. S.; MATOS, F. S.; OLIVEIRA, J. G. Análise de crescimento de diferentes genótipos de citros cultivados sob déficit hídrico. Revista Brasileira de Fruticultura, Jaboticabal, v. 28, n. 3, p. 439-443, 2006.

PEREIRA, W. E.; SIQUEIRA, D. L. de; PUIATTI, M. Growth of citrus rootstocks under aluminium stress in hydroponics. Scientia Agricola, Piracicaba, v. 60 , n. 1, p. 31-41, 2003.

SCHÄFER, G. Caracterização molecular, diagnóstico e avaliação de porta-enxertos na citricultura gaúcha. Dissertação (Mestrado), Universidade Federal do Rio Grande do Sul, 2000, 81 p.

SCHÄFER, G.; SOUZA, P. V. D. DE; KOLLER, O. C.; SCHWARZ, S. F. Desenvolvimento vegetativo inicial de porta-enxertos cítricos cultivados em diferentes substratos, Ciência Rural, v. 36, n. 6, 2006.

SCHMITZ, J. A. K. Cultivo de Poncirus trifoliata (L.) Raf. em recepientes: influência de substratos e de fungos micorrízicos arbusculares. Dissertação (Mestrado). Universidade Federal do Rio Grande do Sul, 1998. 144 p. 